\title{
Postpartum thyroiditis
}

\author{
B. I. HOFFBRAND \\ D.M., F.R.C.P.
}

\author{
S. C. WeBB \\ M.B., B.S.
}

Whittington Hospital, Highgate Hill, London, N.19

\begin{abstract}
Summary
Three women presented 4-6 months after delivery with a goitre and spontaneously changing thyroid function believed to be due to autoimmune thyroiditis. All three patients had transient hypothyroidism and one initially had evidence of thyrotoxicosis. Hypothyroidism in autoimmune thyroiditis is generally regarded as permanent. However, evidence is now accumulating, and is reviewed here, to suggest that relapses or onset with transient thyrotoxicosis and hypothyroidism followed by spontaneous, more or less complete, remission occur in one or more varieties of thyroiditis in the postpartum period.
\end{abstract}

\section{Introduction}

There is increasing evidence that changes in thyroid function tend to occur in the postpartum period in one or more varieties of thyroiditis. Amino et al. $(1976,1977 \mathrm{a})$ have reported a number of cases of transient postpartum hypothyroidism which they attribute to autoimmune thyroiditis. Ginsberg and Walfish (1977) described five patients with transient thyrotoxicosis after delivery, followed, in three cases, by transient hypothyroidism, and in another by permanent hypothyroidism. They attributed at least three of their cases to painless (silent) thyroiditis (Leading Article, 1977).

Three patients have recently been seen in a general medical clinic with goitre and disordered thyroid function showing evidence of spontaneous changes, occurring 4-6 months after delivery. They are reported as further evidence of a significant relationship between thyroiditis and the postpartum period.

\section{Methods}

Serum thyroxine $\left(\mathrm{T}_{4}\right)$ (normal range 55-155 $\mathrm{nmol} / \mathrm{l})$ (Nye et al., 1976), triiodothyronine $\left(\mathrm{T}_{3}\right)$ $(1 \cdot 2-3 \cdot 1 \mathrm{nmol} / \mathrm{l}) \quad\left(\mathrm{T}_{3}\right.$ RIA $\left.\mathrm{Kit}^{*}\right)$ and thyroidstimulating hormone (TSH) (resting less than 4 mu./l) (Hall, Amos and Ormston, 1971) were measured by radioimmunoassay.

The TSH response to thyrotrophin releasing

Correspondence to: Dr B. I. Hoffbrand, Whittington Hospital, Highgate Hill, London, N.19. hormone (TRH) was determined as described by Ormston et al. (1971), $\mathrm{T}_{3}$ uptake $(92-117 \%$ ) was estimated using the Thyopac $3 \mathrm{Kit}^{*}$ and the free thyroxine index (FT index) (55-155) was calculated. Antithyroid microsomal haemagglutination (HA) and antithyroglobulin tanned red cell (TRC) antibody titres were measured by haemagglutination methods using Fujizoki Pharmaceutical and Wellcome kits respectively.

\section{Case reports \\ Case 1}

A 31-year-old woman presented in May 1977 with paraesthesiae affecting all the fingers of the right hand and a painless goitre both noted a few weeks previously. Her first baby had been born in December 1976 after an uneventful pregnancy and delivery. There was no family history of thyroid or autoimmune disease. On examination there was a moderate sized, firm, non-tender, diffuse goitre without signs of hypothyroidism or neurological disease.

Investigations: Serum $\mathrm{T}_{4} 25 \mathrm{nmol} / \mathrm{l}, \mathrm{FT}$ index 22, TSH $>64 \mathrm{mu} . / 1$, thyroid microsomal HA titre $1: 25600$, anti-thyroglobulin TRC titre $1: 10$, ESR $4 \mathrm{~mm} / \mathrm{hr}$. Following treatment with thyroxine the goitre shrank to normal size and consistency and the paraesthesiae cleared; the patient became more alert mentally. Review of old photographs suggested a goitre antedating the pregnancy.

In October 1977, 5 weeks after discontinuing thyroxine, serum $T_{4}$ was $82 \mathrm{nmol} / 1, T_{3} 2 \cdot 3 \mathrm{nmol} / \mathrm{l}$, TSH $3.1 \mathrm{mu} . / \mathrm{l}$; there was an exaggerated response to TRH, the TSH levels at 20 and $40 \mathrm{~min}$ being greater than $128 \mathrm{mu}$./1. The thyroid microsomal HA titre was $1: 102400$ and the thyroglobulin TRC $1: 40$. Six months later the patient was well. The thyroid gland was not abnormal clinically; the serum $\mathrm{T}_{4}$ was $84 \mathrm{nmol} / \mathrm{l}$ and the TSH $2 \mathrm{mu} . / \mathrm{l}$.

\section{Case 2}

A 31-year-old woman had her first baby in February 1977, having had a miscarriage in 1975.

* Radiochemical Centre, Amersham, England. 
In June 1977 she was noted to have a small goitre at which time she felt tired and had a more frequent and looser bowel action than usual. The goitre was diffuse and not tender; the patient was clinically euthyroid. There was a family history of a maternal aunt on thyroid replacement for myxoedema and her daughter, the patient's cousin, gives a history of a thyroid disorder after delivery some years before. She was not taking an oral contraceptive.

Investigations: Serum $\mathrm{T}_{4} 260 \mathrm{nmol} / \mathrm{l}$, FT index $236, T_{3}$ uptake $110 \%$. When repeated ten days later serum $\mathrm{T}_{4}$ was $160 \mathrm{nmol} / \mathrm{l}, \mathrm{FT}$ index 151 , the thyroid microsomal HA titre $1: 1600$ and the thyroglobulin TRC titre $1: 1280$. Twelve weeks after the initial investigations she had put on $3.6 \mathrm{~kg}$ in weight, felt tired, and had regained her normal bowel habit. The goitre was unchanged. There was now clear-cut biochemical evidence of hypothyroidism - serum $T_{4}$ $44 \mathrm{nmol} / 1, \mathrm{~T}_{3} 2 \cdot 3 \mathrm{nmol} / \mathrm{l}$, TSH $62 \mathrm{mu}$./1 rising to $>128$ with TRH. The thyroid microsomal HA titre was unchanged at $1: 1600$ and the thyroglobulin TRC titre lower at $1: 320$.

Three months later, in December 1977, and without treatment, the patient was once more euthyroid (serum $\mathrm{T}_{4} 69 \mathrm{nmol} / \mathrm{l}$, TSH $9 \cdot 1 \mathrm{mu} . / \mathrm{l}$ ) and the thyroid gland was of normal size and consistency. In April 1978, when 16 weeks pregnant, serum $T_{4}$ was $123 \mathrm{nmol} / 1$, FT index 96 , serum TSH $7 \cdot 4 \mathrm{mu} . / 1$, thyroid microsomal HA titre $1: 400$, thyroglobulin TRC titre $1: 40$.

\section{Case 3}

A 28-year-old woman was seen in September 1977 one month after having had her attention drawn to a painless goitre. She had been rather tired for some months, which she attributed to a demanding first baby born in February 1977 after an uneventful pregnancy and delivery. She had had a miscarriage in 1975; there was no family history of thyroid or autoimmune disease. Examination revealed a small, firm, non-tender diffuse goitre without signs of thyroid dysfunction.

Investigations: Serum $\mathrm{T}_{4} 52 \mathrm{nmol} / 1, \mathrm{~T}_{3} 2.6 \mathrm{nmol} / \mathrm{l}$, FT index 46, TSH $15 \mathrm{mu} . / 1$, thyroid microsomal HA titre $1: 25$ 600. Thyroglobulin TRC antibodies not detected. ESR $4 \mathrm{~mm} / \mathrm{hr}$. Five weeks later she felt well and the goitre appeared smaller. Serum $T_{4}$ $81 \mathrm{nmol} / 1, \mathrm{~T}_{3} 2.5 \mathrm{nmol} / \mathrm{l}, \mathrm{FT}$ index $70, \mathrm{TSH}<1.0$ mu./1 but with an exaggerated response, the levels at 20 and $60 \mathrm{~min}$ being 60 and $28 \mathrm{mu}$./1 respectively. The thyroid microsomal HA titre was down to $1: 6400$. In April 1978, fourteen months after delivery, she was well, with a clinically normal thyroid gland. Serum $T_{4}$ was 101 and $T_{3} 2 \cdot 8 \mathrm{nmol} / 1$; FT index was 86; basal TSH was $<1$, and 15.7 and $13.4 \mathrm{mu} . / 1$ at 20 and $60 \mathrm{~min}$ respectively after TRH (a normal response); thyroid microsomal HA titre 1 : 1600; thyroglobulin TRC negative.

\section{Discussion}

The major characteristics of transient postpartum hypothyroidism in the fourteen patients described by Amino et al. (1977a) are thyroid enlargement within 4 months of delivery, hypothyroidism 3-5 months postpartum, spontaneous recovery by 10 months and high titres of antithyroid microsomal antibodies. The authors also noted transient increased circulating thyroid hormones before the development of hypothyroidism in two patients and a low thyroid ${ }^{131}$ I-uptake in a third patient with postpartum transient hyperthyroidism. The latter finding is the hallmark of thyrotoxicosis due to a thyroiditis (Gluck, Nusynowitz and Plymate, 1975) and was recorded in the patients described by Ginsberg and Walfish (1977). Case 2 of the present series had transient thyrotoxicosis (the normal $\mathbf{T}_{3}$ uptake is compatible with mild hyperthyroidism (Havard, 1975)) but radioiodine studies were not done.

The clinical picture of the patients reported here thus resembles those described by Amino et al. (1977a). All three patients having been frankly hypothyroid, are now clinically and biochemicallyo euthyroid although Case 2 shows, 14 months post partum, evidence of thyroid impairment with raised basal TSH level. The third patient at this stage had a normal TRH test. It is possible tha Cases 1 and 3 as well as others of Amino's patients passed through an unrecognized phase of transient thyrotoxicosis. The spontaneously changing thyroid function noted by Amino et al. (1976, 1977a,b), Ginsberg and Walfish (1977) and the present authors, in relation to the postpartum period provides strong evidence of a causal rather than a co-incidental association. There are a number of earlier reports to suggest a relationship between pregnancy and the postpartum period, and autoimmune thyroiditis (Skillern et al., 1956; Parker and Beierwaltes, 1961 ; Nelson and Palmer, 1975).

The nature of the underlying thyroid pathology is uncertain. The high titres of antithyroid microsomal antibodies found by Amino et al. (1976, 1977a) and the present authors, as well as the family history of thyroid disease in Case 2 are a pointer to chronic thyroiditis of an autoimmune aetiology. Transient high levels of this autoantibody do occur in classical subacute thyroiditis but are exceptional (Volpe, Row and Ezrin, 1967). However, two of the patients of Ginsberg and Walfish (1977) had no antithyroid antibodies and they believe that these two, and a third patient had painless subacute thyroiditis (Leading Article, 1977).

It seems probable that a spectrum of thyroid disorders, including Graves' disease (Amino et al., 
1977b), have a tendency to relapse in the postpartum period. The problems in determining the nature of painless thyroiditis with transient thyroid dysfunction are discussed in detail by Dorfman $e t$ al. (1977). The relationship of pregnancy to the thyroid disease is also unclear. A 'rebound phenomenon' following pregnancy-induced remission has been noted in other autoimmune disorders (Oka, 1953; Garsenstein, Pollak and Kark, 1962). Suppression of immune reactions during pregnancy has been noted (Editorial, 1974), and may be relevant in this context.

From a practical point of view, thyroid dysfunction may occasionally provide the explanation for symptoms in the postpartum period and a goitre noted at this time should not be lightly dismissed as due to pregnancy. Thyrotoxicosis or hypothyroidism diagnosed within 6 months of a pregnancy should be suspected of being transient and a period of observation may be warranted. The long-term history of thyroiditis presenting in the postpartum period is uncertain but if, as seems probable, the majority of cases are due to autoimmune thyroiditis, permanent hypothyroidism may eventually develop and long-term follow-up should be provided.

\section{Acknowledgement}

We thank Miss M. F. Crowley, F.R.C.Path., for help with the thyroid function tests.

\section{References}

Amino, N., Miyai, K., Onishi, T., Hashimoto, T., Ishibashi, K. \& Kumahara, Y. (1976) Transient hypothyroidism after delivery in autoimmune thyroiditis. Journal of Clinical Endocrinology and Metabolism, 42, 296.

Amino, N., Miyai, K., Kuro, R., Tanizawa, O., Azukizawa, M., Takai, S., Tanaka, F., Nishi, K., Kawashima, M. \& Kumahara, T. (1977a) Transient postpartum hypothyroidism: Fourteen cases with autoimmune thyroiditis. Annals of Internal Medicine, 87, 155.

Amino, N., Miyai, K., Yamamoto, T., Kuro, R., Tanaka, F., Tanizawa, O. \& Kumahara, Y. (1977b) Transient recurrence of hyperthyroidism after delivery in Graves' disease. Journal of Clinical Endocrinology and Metabolism, 44, 130.

Dorfman, S.G., Cooperman, M.T., Nelson, R.L., Depuy, H., Peake, R.L. \& Young, R.L. (1977) Painless thyroiditis and transient hyperthyroidism without goiter. Annals of Internal Medicine, 86, 24.

EdITORIAL (1974) Immunological changes in women. Lancet, i, 909.

Garsenstein, M., Pollak, V.E. \& Kark, R.M. (1962) Systemic lupus erythematosus and pregnancy. New England Journal of Medicine, 267, 165.

Ginsberg, J. \& Walfish, P.G. (1977) Postpartum transient thyrotoxicosis with painless thyroiditis. Lancet, i, 1125.

Gluck, F.B., Nusynowitz, M.L. \& Plymate, S. (1975) Chronic lymphocytic thyroiditis, thyrotoxicosis and low radioactive iodine uptake. Report of 4 cases. New England Journal of Medicine, 293, 624.

Hall, R., Amos, J. \& Ormston, B.J. (1971) Radio-immunoassay of human serum thyrotrophin. British Medical Journal, 1, 582.

HAVARD, C.W.H. (1975) The assessment of thyroid function. British Journal of Hospital Medicine, 14, 239.

Leading Article (1977) Painless thyroiditis. British Medical Journal, 2, 348.

Nelson, J.C. \& Palmer, F.J. (1975) A remission of goitrous hypothyroidism during pregnancy. Journal of Clinical Endocrinology and Metabolism, 40, 383.

Nye, L., Hassan, M., Willmott, E. \& Landon, J. (1976) Introduction of a rapid simple radio-immunoassay and quality control scheme for thyroxine. Journal of Clinical Pathology, 29, 453.

OKA, M. (1953) Effect of pregnancy on the onset and course of rheumatoid arthritis. Annals of Rheumatic Diseases, 12, 227.

Ormston, B.J., Garry, R., Cryer. R.J., Besser, G.M. \& HALL, R. (1971) Thyrotrophin-releasing hormone as a thyroid function test. Lancet, ii, 10.

Parker, R.H. \& Beierwaltes, W.H. (1961) Thyroid antibodies during pregnancy and in the newborn. Journal of Clinical Endocrinology and Metabolism, 21, 792.

Skillern, P.G., Crile, G., McCullagh, E.P., Hazard, J.B., Lewis, L.A. \& Brown, H. (1956) Struma lymphomatosa: Primary thyroid failure with compensatory thyroid enlargement. Journal of Clinical Endocrinology and Metabolism, 6, 35 .

VolPe, R., Row, V.V. \& Ezrin, C. (1967) Circulating viral and thyroid antibodies in subacute thyroiditis. Journal of Clinical Endocrinology and Metabolism, 27, 1275. 